\title{
Detection of heterozygotes in both parents of homozygous patients with Von Willebrand's disease
}

\author{
YVETTE SULTAN, JACQUELINE SIMEON, AND J. P. CAEN \\ From the Laboratoire d'Hémostase et de Thrombose Expérimentale, Institute de Recherches sur les Maladies \\ du Sang, E.R.A. 335 du C.N.R.S., Université Paris VII, Hôpital Saint-Louis, Paris
}

SYNOPSIS Three patients with severe Von Willebrand's disease are shown to be homozygotes. They were born from unaffected parents. New techniques using a factor-VIII-related antigen assay by the Laurell method and a ristocetin-induced platelet aggregation assay demonstrated abnormalities in these two tests in both parents of the probands. Factor-VIII-related antigen of heterozygotes could not be differentiated from normal factor-VIII-related antigen by the immunodiffusion technique, crossed immunoelectrophoresis, and filtration on a Sepharose 4B column.

Classically Von Willebrand's disease appears to be transmitted phenotypically, at least as an autosomal dominant trait manifested in heterozygotes (Nilsson, Blombäck, and Von Francken, 1957; Raccuglia and Neel 1960; Barrow and Graham, 1964; Cornu, 1965; Meyer, Larrieu, Maroteaux, and Caen, 1967). However the clinical expression of the disease has been reported to vary widely. Two facts remain unclear concerning the inheritance of the disease: first, more consanguineous parents than expected (Cornu et al, 1961) have been found in the heredity of patients with Von Willebrand's disease, and secondly severely affected patients were often born from unaffected parents (Verstraete, 1963) with no history of bleeding in the family, suggesting that the disease could be transmitted on a recessive mode.

In the present study three severely affected patients from unrelated families, whose parents were available for investigation, show evidence that both parents had anomalies without clinical manifestations.

Previous investigations of these three families using the classical tests (bleeding time, platelet retention on glass beads, factor VIII coagulant assay) failed to demonstrate clear-cut abnormalities in the parents but a factor VIII immunological assay and ristocetin-induced platelet aggregation tests allowed a defect in both parents in each family to be detected.

Attempts were made to compare the characteristics of factor-VIII-related antigen in heterozygotes with normal factor-VIII-related antigen. Neither

Received for publication 18 November 1974. immunodiffusion in agarose nor crossed immunoelectrophoresis nor isolation of factor VIII on Sepharose 4 B columns showed differences between normal factor VIII and factor VIII in heterozygote subjects.

\section{Methods}

\section{BLEEDING TIME}

The bleeding time was determined by the method of Ivy, as modified by Borchgrevink (1960). Using this method normal individuals have a bleeding time of less than 10 minutes.

\section{PLATELET RETENTION}

Platelet retention to glass beads was measured by the method of Bowie (1969).

COAGULATION AND IMMUNOLOGICAL TESTS Coagulation and immunological tests were performed on blood collected on $3.8 \%$ sodium citrate (9 volumes of blocd to 1 volume of anticoagulant).

\section{FACTOR VIII ACTIVITY}

Factor VIII coagulant activity was determined by a one-stage assay as described by Soulier and Larrieu (1953) using the kaolin-activated partial thromboplastin time and plasma of a severe haemophiliac as substrate.

QUANTITATION OF FACTOR-VIII-RELATED ANTIGEN

Factor-VIII-related antigen was quantitated by 
electroimmunoassay (Laurell, 1960), using rabbit antiserum to human factor VIII. Human factor VIII was purified according to the technique of Marchesi et al (1972) and rabbits were immunized with $0.5 \mathrm{mg}$ purified factor VIII in Freund's complete adjuvant once a week for three weeks. Blood was collected 10 days after the last injection, allowed to clot, the serum heated at $56^{\circ} \mathrm{C}$ for one hour and adsorbed with Al $(\mathrm{OH})_{3}$. Sera with factor VIII neutralizing activity were adsorbed with the supernatant of normal human plasma cryoprecipitate. Adsorbed antiserum gave only one peak on crossed immunoelectrophoresis with normal plasma and no precipitation with the plasma of patient with severe Von Willebrand's disease. The antiserum was used at the concentration of 0.3 per $\mu 1$ in a $1 \%$ agarose gel. Ten $\mu \mathrm{l}$ of plasma was allowed to migrate in antibody containing agarose on the Laurell apparatus for 24 hours at $4^{\circ} \mathrm{C}$ under 350 volts with Laurell buffer $\mathrm{pH} 8.6$. The plates were washed for 24 hours in saline, dried, and stained with Coomasie brilliant blue. Peak heights of four dilutions of a normal pooled plasma gave a straight line plot on log-log paper.

\section{IMMUNOELECTROPHORESIS}

Double dimensional immunoelectrophoresis (Laurell, 1965) was performed either on plasma or cryoprecipitate. Ten $\mu$ l of the samples was allowed to migrate for five hours in the first dimension and for 18 hours in the second dimension in agarose containing antiserum to factor VIII in the same buffer.

\section{IMMUNODIFFUSION}

Immunodiffusion methods were used to compare the identity of cryoprecipitate from normal plasma and cryoprecipitate from parent plasma against factor VIII antiserum. The same rabbit antiserum (10 $\mu \mathrm{l})$ as for the Laurell technique was used in a dilution $1: 10$ and wells were filled with five times $10 \mu \mathrm{l}$ of cryoprecipitate. The immunodiffusion was stopped at 24 hours.

VON WILLEBRAND'S FACTOR ACTIVITY

The Von Willebrand's factor activity was estimated by the ristocetin-induced platelet aggregation assay according to the technique of Weiss, Hoyer, Rickless, Varma, and Rogers (1973) slightly modified: blood

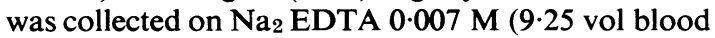
and 0.75 vol EDTA). Normal platelets were washed twice in Tris-EDTA buffer ( 1 vol EDTA, $49 \mathrm{vol}$ Tris buffer) and resuspended in Tris buffer $\mathrm{pH} 7 \cdot 4(\mathrm{NaCl}$ $0 \cdot 138 \mathrm{M}, \mathrm{KCl} 0.05 \mathrm{M}$, Tris $0.015 \mathrm{M})(400000$ platelets per $\mathrm{cmm}$ ) according to Cronberg and Caen (1971).
Ristocetin (Lundbeck) ${ }^{1}$ solution $4 \mathrm{mg}$ per $\mathrm{ml}$ was made up in the same buffer.

The test system in the aggregometer (Labintec) consisted of $0.2 \mathrm{ml}$ solution of washed platelets, $0 \cdot 1$ plasma dilutions $(1: 2,1: 4,1: 8)$, and $0 \cdot 1$ ristocetin solution.

A calibration curve was obtained by plotting the velocity of platelet aggregation versus plasma dilutions. A standard pool of normal plasma was used for the calibration curve, allowing conversion to a percentage of the Von Willebrand factor activity. The normal range of the ristocetin-induced platelet aggregation assay was established from 35 normal plasmas.

Factor VIII was isolated at $4^{\circ} \mathrm{C}$ using a $2.5 \mathrm{~cm}$ by $50 \mathrm{~cm}$ glass column packed with Sepharose $4 \mathrm{~B}$ (Pharmacia fine chemicals) on cryoprecipitate digested by alpha-chymotrypsin according to Marchesi et al (1972). The column was eluted with Tris $\mathrm{NaCl}$ buffer, $\mathrm{pH} 7 \cdot 4$, collecting $3.5 \mathrm{ml}$ aliquots.

Aliquots were immediately assayed for factor VIII coagulant activity and protein concentration. Then four aliquots were pooled and concentrated up to 14 times by dialysis against powdered Ficoll and tested for factor-VIII-related antigen and ristocetininduced platelet aggregation.

\section{Results}

FAMILY 1

The family pedigree is shown in figure 1 .

\section{FAMILY 1}

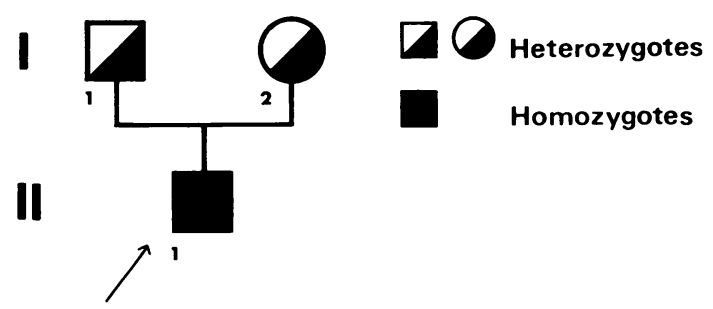

Fig 1 Genealogical tree of family 1.

The proband $\mathrm{II}_{1}$ is a 16-year-old boy affected by a severe haemorrhagic disease. Ecchymoses were present in infancy and bleeding was noted after vaccination. Since then he has been affected mainly by bleeding from the gums after tooth extractions, and recurrent haemarthroses of one ankle. $\mathrm{He}$ is the

${ }^{1}$ H. Lundbeck \& Co. A/S, Ottiliavej 7-9, DK 2500 Copenhagen Valby (Denmark) 


\begin{tabular}{|c|c|c|c|c|c|}
\hline \multirow[t]{2}{*}{ Family 1} & \multirow{2}{*}{$\begin{array}{l}\text { Bleeding Time } \\
\text { (Ivy min) }\end{array}$} & \multirow{2}{*}{$\begin{array}{l}P T T \\
(\mathrm{sec})\end{array}$} & \multicolumn{3}{|l|}{ Factor VIII } \\
\hline & & & $\begin{array}{l}\text { Coagulant Activity } \\
(\%)\end{array}$ & $\begin{array}{l}\text { Related Antigen } \\
(\%)\end{array}$ & $\begin{array}{l}\text { RIPA } \\
(\%)\end{array}$ \\
\hline $\begin{array}{l}\text { II } I_{1} \text { Proband } \\
I_{1} \\
I_{2} \\
\text { Control }\end{array}$ & $\begin{array}{r}>30 \\
5 \\
5 \\
<10\end{array}$ & $\begin{array}{c}140 \\
55 \\
60 \\
55-60\end{array}$ & $\begin{array}{ll} & 1-3 \\
& 54 \\
77 \\
\text { SD } & 98 \cdot 2 \\
31 \cdot 77\end{array}$ & $\begin{array}{c}0 \\
20 \\
25 \\
94 \cdot 34 \\
\text { SD } 29 \cdot 81\end{array}$ & $\begin{array}{c}0 \\
18 \\
22 \\
102 \cdot 88 \\
\text { SD } 32 \cdot 80\end{array}$ \\
\hline
\end{tabular}

Table I Haematological data for family 1

only son of unrelated parents. No bleeding tendency could be found in any member of the family.

Haemostasis data are summarized in table $I$.

In the proband the bleeding time is over 30 minutes and factor VIII coagulant activity is between 1 and $3 \%$. No factor-VIII-related antigen could be detected in his plasma by the Laurell technique and no aggregation could be induced by ristocetin using his own plasma and normal platelets.

In the parents $I_{1}$ and $I_{2}$ the bleeding time is normal. Factor VIII coagulant activity is slightly decreased in the father but is in the normal range in the mother.

Factor-VIII-related antigen was significantly decreased in both parents as was the ristocetin-induced platelet aggregation assay, which paralleled the level of factor-VIII-related antigen. These levels are more than 2 standard deviations below the normal mean.

FAMILY 2

The family pedigree is shown in figure 2 .

The proband, $\mathrm{IV}_{1}$, is an 18-year-old girl severely affected by a haemorrhagic disease. Since childhood she has been troubled by prolonged gingival bleeding and recurrent episodes of tonsillar haemorrhages. Haemarthrosis of the hip was noted at the age of 12. She is the eldest daughter of a consanguineous marriage. No bleeding tendency could be found either in her parents or in her two younger sisters.

The haemostasis data are reported in table II.

The proband showed the characteristics of a

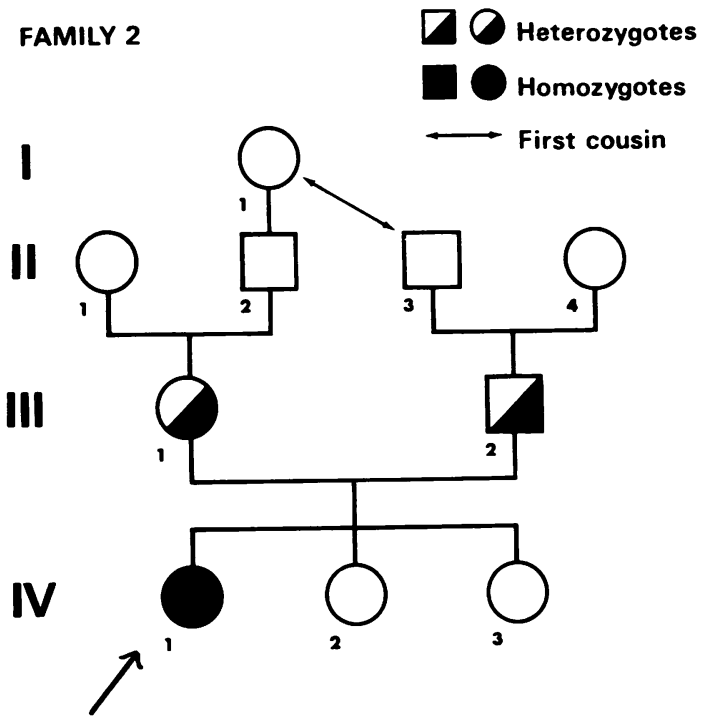

Fig 2 Genealogical tree of family 2.

severe Von Willebrand's disease. The bleeding time is longer than $\mathbf{3 0}$ minutes and factor VIII coagulant activity less than $4 \%$. No factor-VIII-related antigen could be detected by the Laurell technique and no ristocetin-induced aggregation could be seen either in the patient's platelet-rich plasma or with washed normal platelets in the patient's plasma.

Both parents have normal bleeding times and their

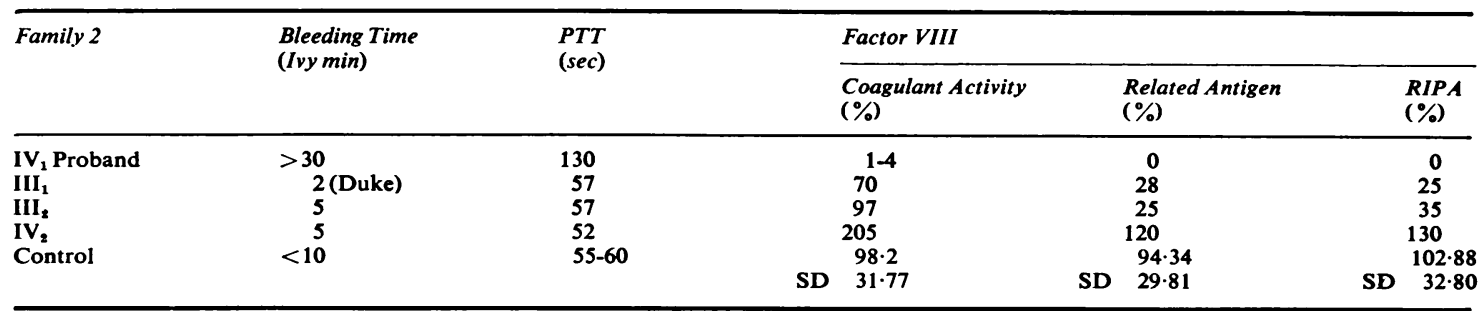

Table II Haematological data for family 2 
factor-VIII-coagulant activity is in the normal range. The factor-VIII-related antigen is $28 \%$ in the mother and $25 \%$ in the father; the ristocetin-induced aggregation is decreased in the same proportion. In the only sister of the proband who could be tested (IV2), the bleeding time was normal, and the procoagulant activity of factor VIII was slightly increased. Factor-VIII-related antigen and ristocetin-induced aggregation were normal.

FAMILY 3

The family pedigree is shown in figure 3 .

FAMILY 3

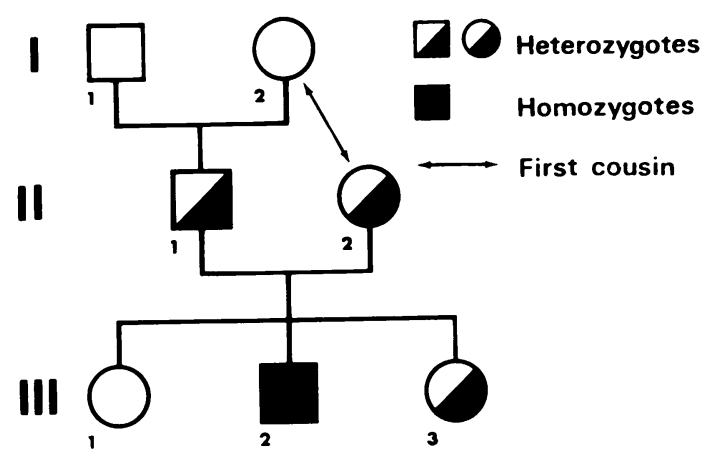

Fig 3 Genealogical tree of family 3.

The proband is a 14-year-old boy affected since birth by a severe haemorrhagic disease. He was born in Tunisia from a consanguineous marriage and considered to be a haemophiliac. He was referred to this department for treatment of a recurrent haemarthrosis of the right ankle. For two years bleeding occurred once or twice a month in the same joint. No history of bleeding could be detected in the parents or in any other family members.

Haemostasis data are shown on table III.
The proband $\mathrm{III}_{2}$ has a bleeding time longer than 30 minutes. The factor VIII coagulant activity was less than $5 \%$ and platelet retention to glass beads was very low. No antigenic material could be demonstra- $\overrightarrow{0}$ ted using antifactor VIII antiserum. Ristocetin did 듬 not induce platelet aggregation when tested with the patient's plasma.

The parents have a normal bleeding time and normal platelet retention on glass beads. The factor VIII coagulant assay is normal in the father $\vec{\circ}$ and slightly decreased in the mother. Factor-VIIIrelated antigen and ristocetin-induced platelet $\stackrel{\omega}{\circ}$ aggregation assay were significantly reduced in both parents.

The sisters of the proband were examined using $\infty$ the same tests. In both of them bleeding time was normal, as well as platelet retention on glass beads. $\stackrel{\bullet}{0}$ In the oldest girl ( III $\left._{1}\right)$, factor VIII coagulant activity, 을 factor-VIII-related antigen and ristocetin-induced platelet aggregation assay were normal, but in the youngest $\left(\mathrm{III}_{3}\right)$, factor VIII coagulant activity, factor-VIII-related antigen, and ristocetin aggregation were decreased, suggesting that she is a heterozygote for the Von Willebrand abnormality.

Properties of Factor-VIII-related Antigen in Heterozygous Members of the Three Families

Immunodiffusion was used to compare antigenic properties of factor-VIII-related antigen in the $\overrightarrow{\overrightarrow{0}}$ cryoprecipitate of heterozygous members of the three families. As can be seen from fig 4 complete immunological identity is found between factorVIII-related antigen of normal cryoprecipitate and that of the heterozygous parents. No precipitation line was seen with the cryoprecipitates of the three probands.

In double-dimensional immunoelectrophoresis the peak of precipitation (fig 5) is decreased in size compared with the peak obtained in the same conditions with normal cryoprecipitate but migrates at the same pace and has the same pattern. Using the same technique with the patient's plasma instead of $\widetilde{\sigma}$

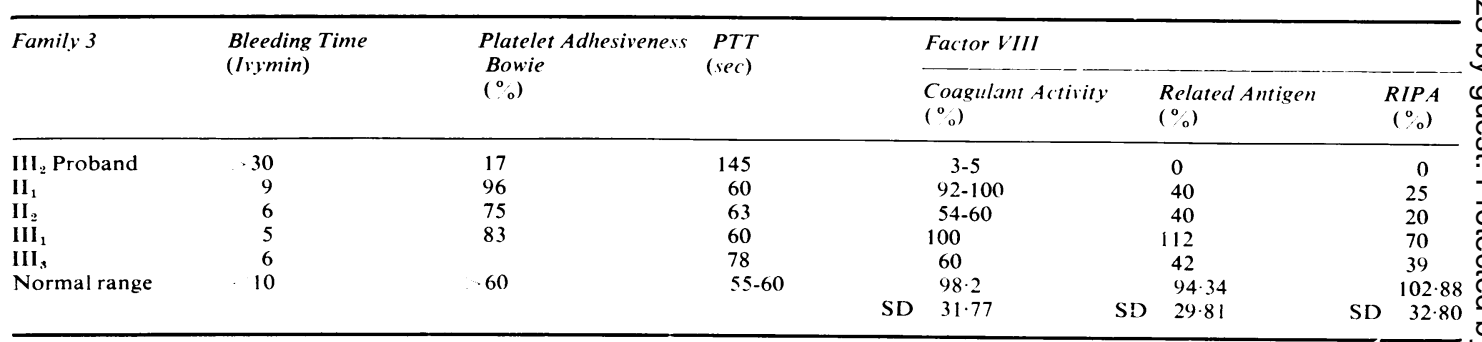

Table III Haematological data for family 3 

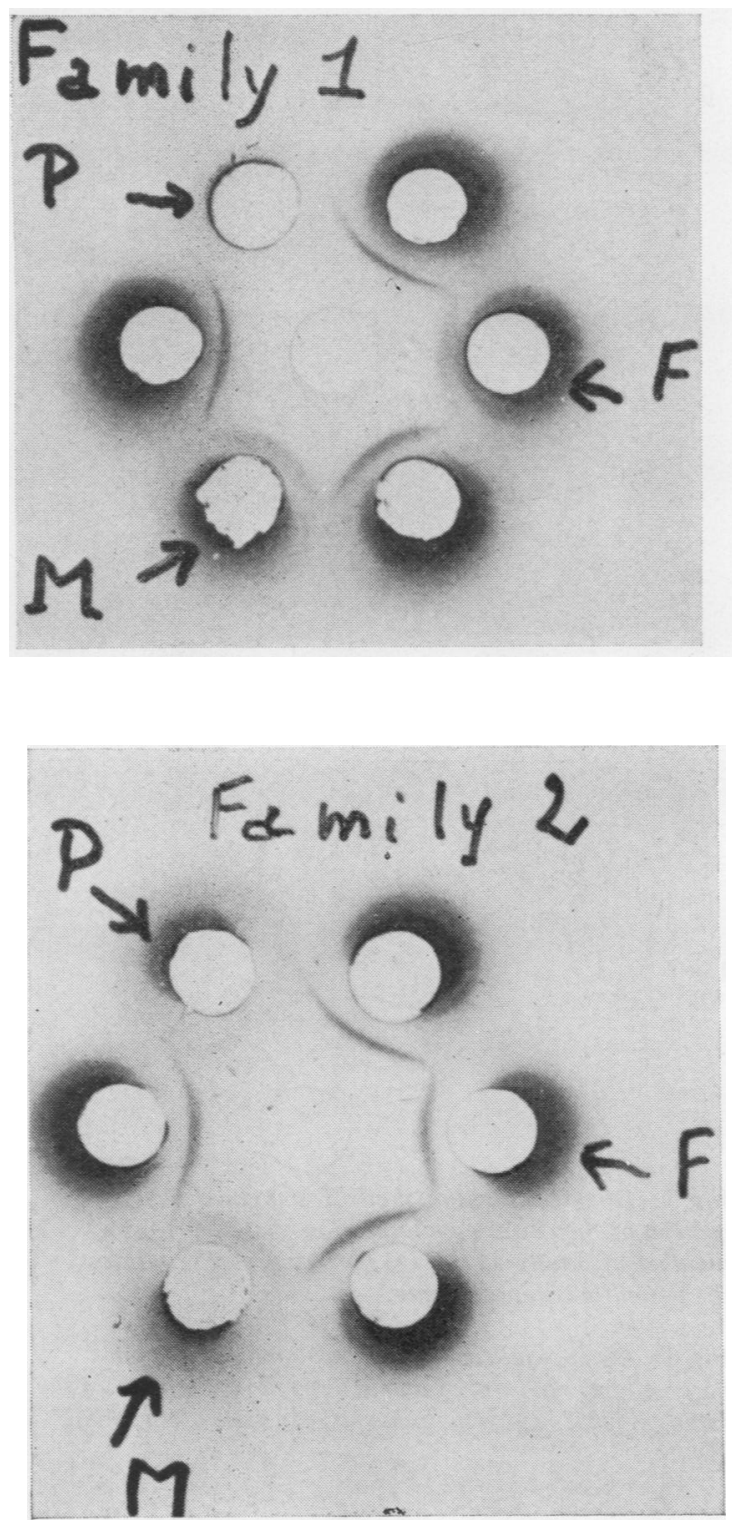

cryoprecipitate the migration pattern was the same as the one of the control, only decreased in size (fig 6).

\section{Isolation of Factor VIII on a Sepharose 4 B Column}

Isolation of factor VIII on a Sepharose 4 B column was carried out using the cryoprecipitate of the father (I1 of family 1) assumed to be a heterozygote.

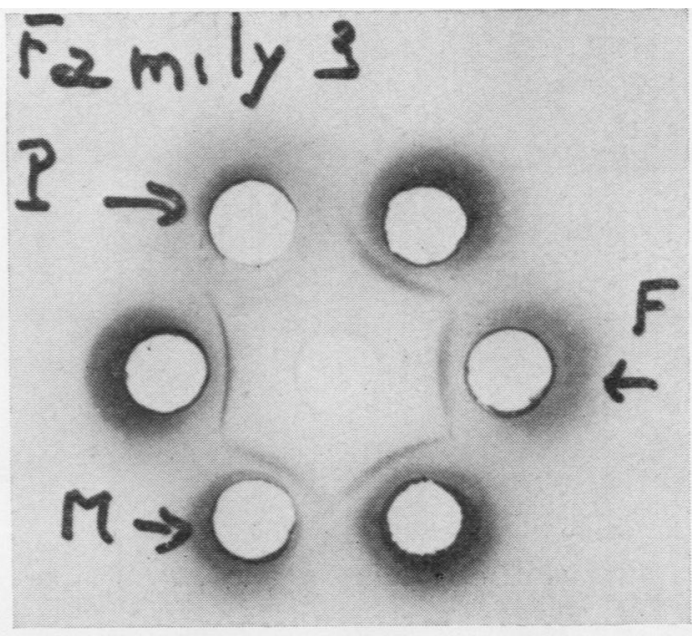

Fig 4 Immunodiffusion patterns of three members of the three families. P Cryoprecipitate of the probands; F cryoprecipitate of the fathers; $M$ cryoprecipitate of mothers. The three other wells have been filled with normal cryoprecipitate.
After step-wise alpha-chymotryptic digestion, $7 \mathrm{ml}$ of plasma cryoprecipitate was placed on a 2.5 by $50 \mathrm{~cm}$ column packed with Sepharose 4 B. Factor VIII coagulant activity was eluted in the void volume and the elution peak was identical to the peak obtained with normal cryoprecipitate (fig 7); factor-VIII-related protein was eluted in the same fraction as factor VIII coagulant activity but in a reduced amount compared with a normal 


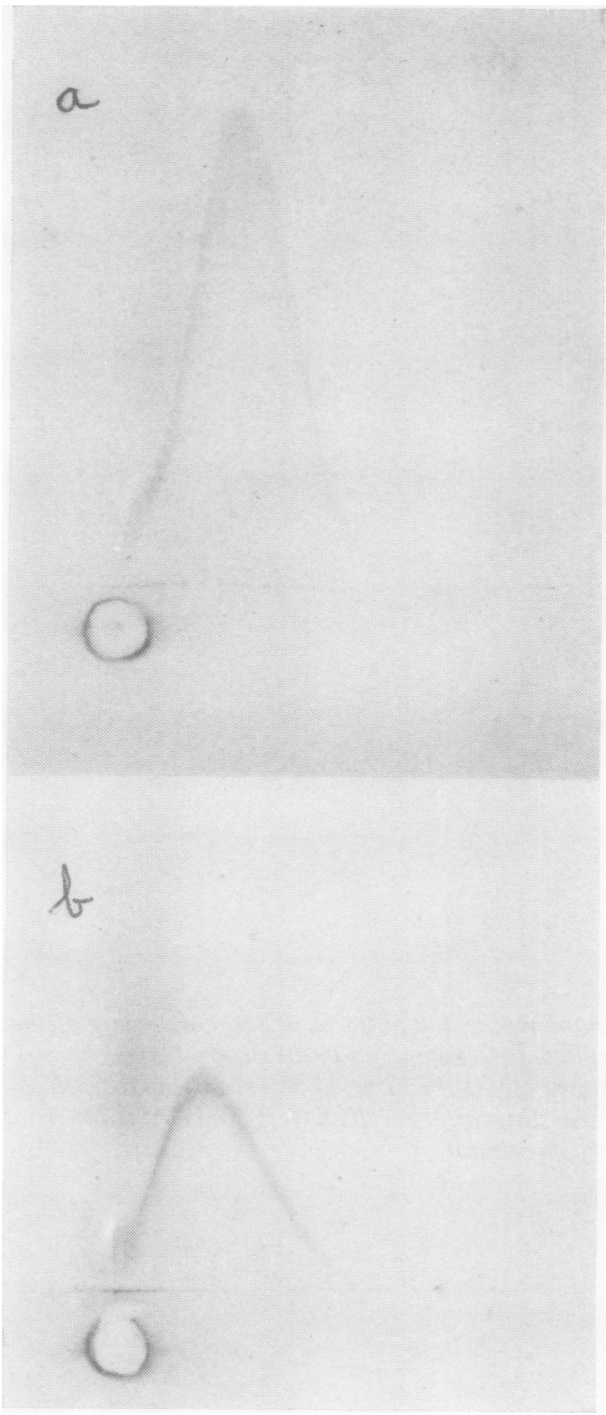

Fig 5

cryoprecipitate. Ristocetin-induced aggregation activity of these fractions correlated with factorVIII-related antigen concentration.

\section{Discussion}

Von Willebrand disease has a variable clinical expression from one case to another. In some very severely affected patients, the literature suggests the possibility of homozygosity. In some cases this suggestion is based on positive data, such as moderate abnormalities in both parents, as in a family

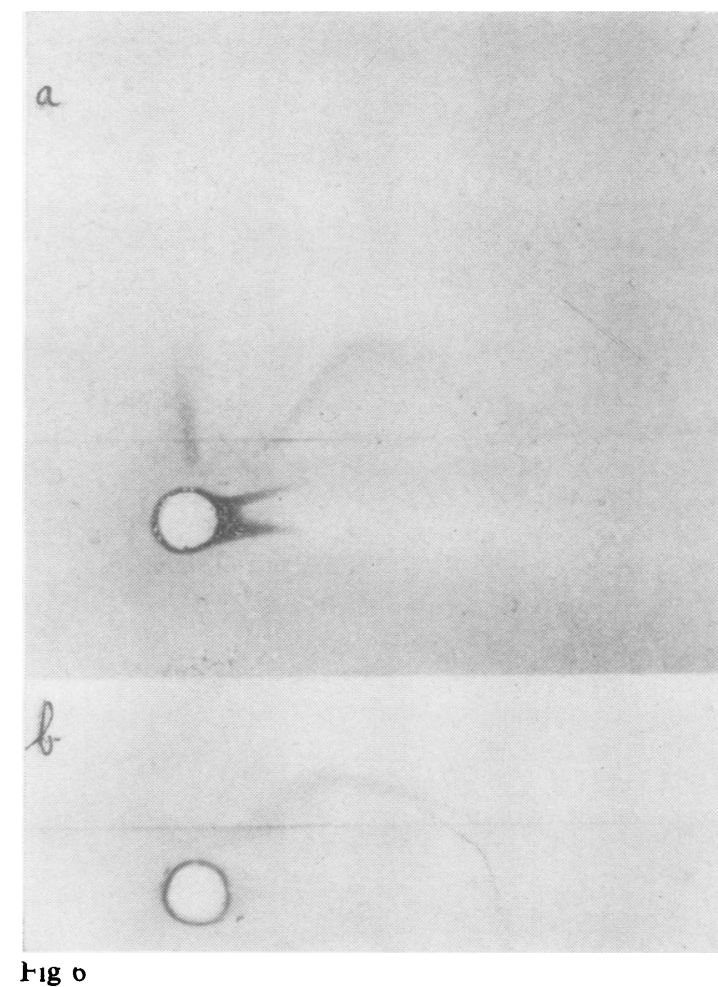

Fig 5 Double-dimensional electroimmunodiffusion pattern of the cryoprecipitate of one heterozygous member of family 3 (II); (a) normal cryoprecipitate; (b) patient's cryoprecipitate.

Fig 6 Double-dimensional electroimmunodiffusion pattern of the plasma of one heterozygous member of family 3 (II); (a) normal plasma, (b) patient's plasma.

reported by Barrow, Heindel, Roberts, and Graham (1964) and in two of the families reported by Silver (1973). But this mode of inheritance is mainly suggested by indirect or negative arguments: the high frequency of consanguineous parents (Cornu, 1965) and the absence of bleeding disorders in both parents of severely affected children (Verstraete, 1963).

The three families we report here showed both these characteristics. Two of them are consanguineous and no bleeding tendency or abnormal bleeding time could be found in the parents. 


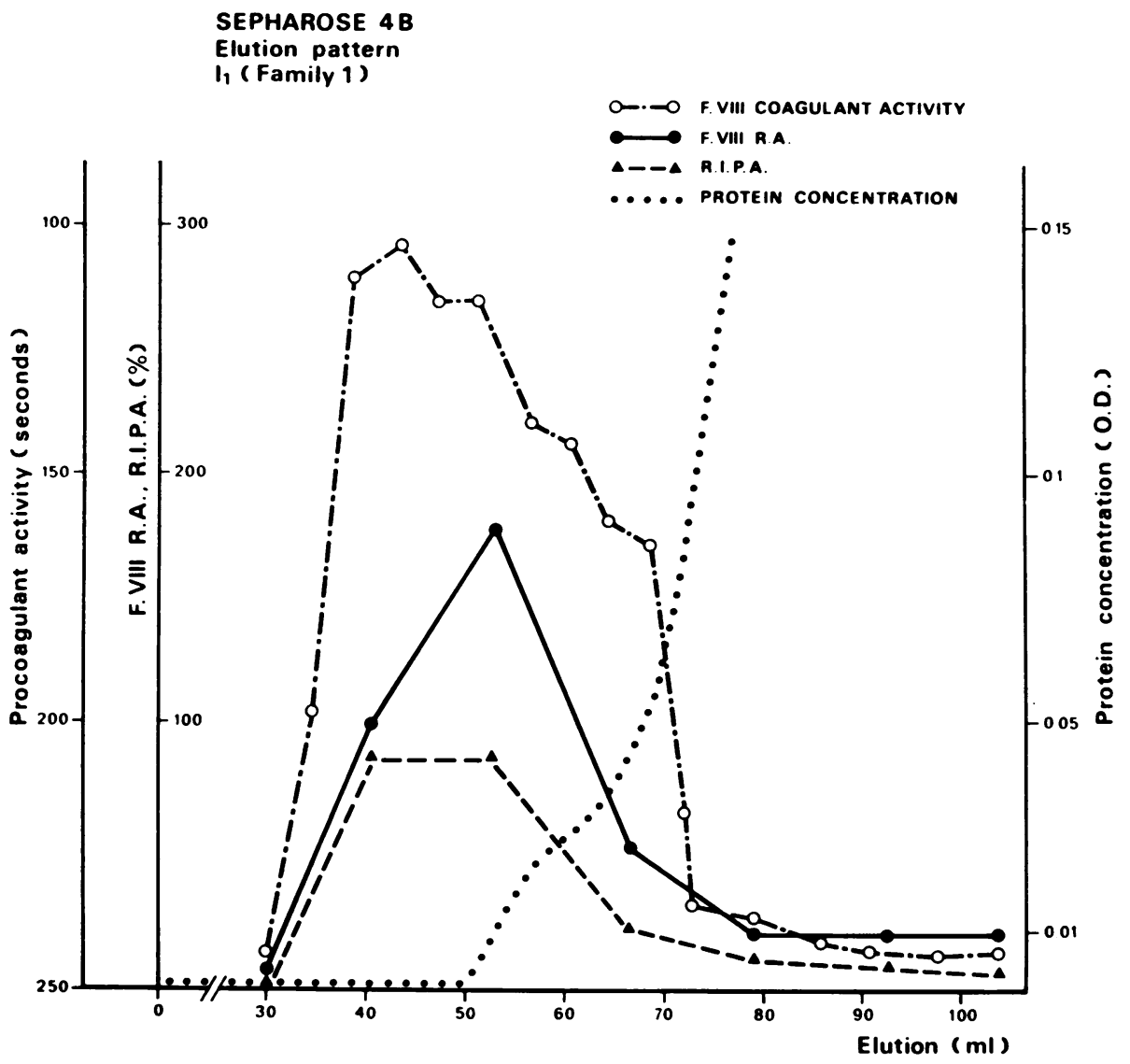

Fig 7 Sepharose $4 B$ Elution pattern on the cryo-precipitation of $I_{1}$ (family 1 ).

The three probands have in common a severe bleeding disease with bleeding times over 30 minutes, very low factor VIII coagulant activity, no factorVIII-related antigen, and the absence of the plasma factor necessary for ristocetin-induced platelet aggregation. In contrast to this severe haemorrhagic disease the parents in the three families have no bleeding tendency and a normal bleeding time. With the three tests previously used, namely, bleeding time, platelet retention on glass beads, and factor VIII coagulant activity, in none of the three families could heterozygotes be detected. In two cases, factor VIII coagulant activity was slightly decreased ( $\mathrm{l}_{1}$ of family 1 and $\mathrm{II}_{2}$ of family 3 ) in one of the parents, suggesting the possibility of a dominant inheritance through one of the parents.

Immunological assays for factor-VIII-related antigen and ristocetin assay for Von Willebrand factor have demonstrated decreases in factor-VIII- related antigen and Von Willebrand factor in both parents, leading to the postulate that both parents are heterozygotes.

Moreover, in the third family presented, the three children show the three possible patterns for recessive inheritance: $\left(\mathrm{II}_{1}\right)$ is normal, $\left(\mathrm{III}_{2}\right)$ is the proband and is a homozygote, and $\left(\mathrm{III}_{3}\right)$ is a heterozygote.

In heterozygous members of the family, the decreases in factor-VIII-related antigen and Von Willebrand factor suggest the following conclusions. (1) There appears to be no relationship between factor VIII coagulant activity which is, in most cases, in the normal range, and factor-VIII-related antigen or Von Willebrand factor which are lower than the normal range. (2) Platelet retention on glass beads, when tested, was normal and the bleeding time in all heterozygotes was normal. One can assume that this low level of factor-VIII-related antigen is 
sufficient to provide at least a normal bleeding time and to provoke a normal adhesion/aggregation of platelets to subendothelial tissue.

Immunological studies by the immunodiffusion method or double-dimensional electrophoresis and isolation of factor VIII on Sepharose $4 \mathrm{~B}$ failed to show any difference between normal factor-VIIIrelated antigen and factor-VIII-related antigen in heterozygous patients suggesting that the disorder in these families is purely a quantitative one.

These experiments lend further substance to the inheritance theories in Von Willebrand's disease (Graham, 1973). The detection of heterozygotes for Von Willebrand's disease by these two tests seems to demonstrate that unaffected subjects can carry the defect and that carriers may be more frequent than previously supposed. The heterozygous defect has very variable penetrance: all the way from no phenotypic disease, as in both parents of the three families, to a fairly severe clinical disease, and the extremely severe cases of Von Willebrand's disease could represent homozygous patients.

Barrow and Graham (1964) suggest that homozygote and heterozygote patients with Von Willebrand's disease may have a different response to haemophilic plasma infusions. The response of our patients to plasma infusions appears to offer a further opportunity for understanding the genetic problems raised by this disease and is now under investigation.

\section{References}

Barrow, E. M., and Graham, J. B. (1964). Von Willebrand's disease. Progr. Haemat., 4, 203-221.
Barrow, E. M., Heindel, C. C., Roberts, H. R., and Graham, J. B. $\stackrel{2}{2}$ (1965). Heterozygosity and homozygosity in Von Willebrand's ? disease. Proc. Soc. exp. Biol. (N. Y.), 118, 684-687.

Borchgrevink, C. F. (1960). A method for measuring platelet adhesiveness in vivo. Acta med. scand., 168, 157-164.

Bowie, E. J. W., Owen, C. A., Jr., Thompson, J. H., and Didisheim, P. 으 (1969). Platelet adhesiveness in Von Willebrand's disease. Amer. $\bar{O}$ J. clin. Path., 52, 69-77.

Cornu, P., Larrieu, M. J., Caen, J., and Bernard, J. (1961). Maladie de $\frac{\rho}{\partial}$ Willebrand: étude clinique, génétique et biologique à

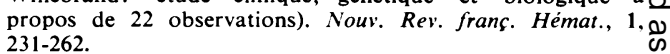

Cornu, P. (1965). Maladie de Willebrand. Path. et Biol, 13, 546-553 Cronberg, S., and Caen, J. P. (1971). Platelet aggregation in washed suspensions. Scand. J. Haemat., 8, 161-168.

Graham, J. B. (1973). The nature of the antihemophilic factor (AHF): $\vec{\omega}$ introduction and overview. In Thrombosis: Mechanisms and Control, edited by K. M. Brinkhous, pp. 177-183. Schattauer, Stuttgart, and New York.

Laurell, C. B. (1965). Antigen-antibody crossed electrophoresis. iN Analyt. Biochem., 10, 358-361.

Laurell, C. B. (1966). Quantitative estimation of proteins by electro- $\rightarrow$ phoresis in agarose gel containing antibodies. Analyt. Biochem. $\omega$ 15, 45-52.

Marchesi, S. L., Shulman, N. R., and Gralnick, H. R. (1972). Studies on the purification and characterization of human factor VIII. J. clin. Invest., 51, 2151-2161.

Meyer, D., Larrieu, M. J., Maroteaux, P., and Caen, J. P. (1967). Biological findings in Von Willebrand's pedigrees: implications for inheritance. J. clin. Path., 20, 190-194.

Nilsson, I. M., Blombäck, M., and Von Francken, I. (1957). On an inherited autosomal hemorrhagic diathesis with antihemo- $\bullet$ philic globulin (AHG) deficiency and prolonged bleeding time. $\mathrm{G}$ Acta med. scand., 159, 35-57.

Raccuglia, G., and Neel, J. V. (1960). Congenital vascular defect associated with platelet abnormality and antihemophilic factor deficiency. Blood, 15, 807-829.

Silwer, J. (1973). Von Willebrand's disease in Sweden. Acta paediat. scand., Suppl. 238.

Soulier, J. P., and Larrieu, M. J. (1953). Measurement of thrombo- $\frac{O}{(D}$ plastic factors and profactors in plasma. I. Deficits in thromboplastin: study of reagents: measurement of antihemophilic and $\overrightarrow{7}$ of platelet activities. J. Lab. clin. Med., 41, 849-864.

Verstraete, M. (1963). The hereditary pattern in angiohaemophilia. Thrombus. Diath. haemorrh. (Stuttg.), 9, Suppl. 2, 133.

Weiss, H. J., Hoyer, L. W., Rickless, F. R., Varma, A., and Rogers, J. (1973). Quantitative assay of a plasma factor, deficient in Von Willebrand's disease that is necessary for platelet aggregation: relationship to factor VIII procoagulant activity and antigen? content. J. clin. Invest., 52, 2708-2716. 